\title{
Relativização na Língua Kaingang
}

\author{
Relativization in Kaingang Language
}

\author{
Luciana Pereira TABOSA * \\ Ludoviko C. dos SANTOS **
}

Resumo: O presente trabalho volta-se à descrição e análise das orações relativas da língua kaingang, que pertence à família linguística Jê, do tronco Macro-Jê. A fundamentação teórica adotada para investigar as orações relativas nessa língua tem como base autores que abordam essas orações sob a perspectiva funcional, tais como Givón (1979), Keenan (1985), Keenan e Comrie (1997), Payne (1997) e Andrews (2007). Segundo esses autores, a oração relativa é uma oração subordinada que funciona como modificadora do núcleo de um sintagma nominal. A análise e descrição das orações relativas têm como objetivo constatar como se manifestam essas orações em relação aos parâmetros que permitem distinguir as orações relativas nas línguas. $\mathrm{O}$ corpus constitui-se de dados coletados com informantes indígenas da Terra Indígena Apucaraninha, localizada no município de Tamarana-PR. A análise aponta que a língua kaingang não apresenta uma relativização formal, ou seja, com o emprego de algum relativizador, sendo que a subordinação da oração relativa à oração principal se dá em termos semânticos. Embora não ocorram marcas gramaticais no sintagma nominal relativizado, a oração relativa cumpre seu papel de modificadora, atendendo aos propósitos comunicativos.

Palavras-chave: Kaingang. Orações relativas. Descrição.

Abstract: 'This paper it's about the description and analysis of relative clauses of kaingang language, which belongs to the linguistic family Ge, trunk

\footnotetext{
* Mestre (2006) e Doutoranda em Estudos da Linguagem pela Universidade Estadual de Londrina. Contato: lu.tabosa04@gmail.com.

** Mestre (1979) em Letras pela Pontifícia Universidade Católica do Paraná. Doutorado (1997) em Linguística pela Universidade Federal de Santa Catarina (1997). Professor da Universidade Estadual de Londrina. Contato: lilukabi@uel.br.
} 
Macro-Ge. The theoretical framework adopted to investigate the relative clauses of that language is based on authors who address their thinking under the functional perspective, such as Givón (1979), Keenan (1985), Keenan and Comrie (1997), Payne (1997) and Andrews (2007). According to these authors, the relative clause is a subordinate clause that functions as a modifier of the core of a noun phrase. The analysis and description of relative clauses aim to see how these clauses are manifested into those parameters that distinguish the relative clauses in languages. The corpus consists of data collected with indigenous informants from Apucaraninha Indigenous Land, located in the city of Tamarana-PR. The analysis indicates that the kaingang language does not present a formal relativization, in other words, with the use of any relativizing, the subordination of phrases on the main clause occurs in semantic terms. Although there are no grammatical marks in the relativized noun phrase, relative clause fulfills its role of modifier, giving communicative purposes to phrases.

Key-words: Kaingang. Relative clauses. Description.

\section{Introdução}

No Brasil, existem cerca de 180 línguas indígenas e um número reduzido de pesquisadores que se dedicam a elas. Muitas dessas línguas têm pouca descrição ou sequer foram objetos de pesquisa, fato que destaca a importância e a necessidade de que mais linguistas se dediquem ao seu estudo.

Conforme elucida Seki (2000), embora o processo de implementação da linguística no Brasil tenha ocorrido somente a partir dos anos 60, o desenvolvimento, nesta área, de um campo dedicado aos estudos das línguas indígenas tardou ainda mais. No fim dos anos 50, o Summer Institute of Linguistics (SIL) iniciou atividades no Brasil, por meio de um convênio com o Museu Nacional, cujo intuito seria descrever as línguas indígenas e formar linguistas brasileiros. No entanto, sendo uma instituição missionária, associou o seu trabalho linguístico ao desenvolvimento de catequese. É evidente que essa instituição contribuiu para a documentação das línguas indígenas, embora o número e a qualidade de trabalhos produzidos deixaram a desejar por falta de uma visão de conjunto das línguas estudadas como, por exemplo, a produção de gramáticas com terminologia linguística acessível e dicionários. Foi somente a partir da década de 80 que aumentou, consideravelmente, o 
número de linguistas brasileiros engajados no estudo das línguas indígenas, entretanto, esse número ainda é pequeno se considerarmos a quantidade de línguas faladas no Brasil.

Uma dessas línguas é o kaingang, que pertence à família linguística Jê, do tronco Macro-Jê. A população kaingang é estimada em 37.400 pessoas, ocupando a terceira posição entre os povos indígenas mais numerosos do país e constituindo o maior grupo indígena pertencente à família linguística Jê. Os kaingang habitam 32 Terras Indígenas nos Estados de São Paulo, Paraná, Santa Catarina e Rio Grande do Sul.

Estudos no nível morfossintático da língua começaram no início do século XX com a organização de uma gramática (1918) e um dicionário (1920), publicados por Frei Mansueto B. de Val Floriana. Apesar de ser um material riquíssimo, constitui-se apenas como uma referência aos estudos morfossintáticos, tendo em vista que as análises desenvolvidas pelo autor são pouco sistemáticas e se baseiam nos conhecimentos gramaticais da época. Rosário F. Mansur Guérios (1942, 1945) e Herbert Baldus (1947) abordaram aspectos morfossintáticos, porém de forma não sistemática. Destacam-se os trabalhos de Ursula Wiesemann, missionária e linguista do SIL. Esta pesquisadora estabeleceu a ortografia oficial da língua kaingang e publicou trabalhos voltados a fonologia e morfossintaxe (WIESEMANN, 1972, 1974).

A partir da década de 80 intensificam-se os estudos acadêmicos voltados à língua kaingang, com a publicação de dissertações e teses em instituições brasileiras: Cavalcante (1987), Teixeira (1988), Nascimento (1995), Silva (1996), D’Angelis (1998), Bomfoco (2004), Tabosa (2006), Gonçalves (2007, 2011), Almeida (2008), Abreu (2009), Maria Silva (2011), Moana Silva (2011) e Andrade (2012).

Para contribuir com os estudos no nível morfossintático da língua, estamos desenvolvendo uma pesquisa de doutorado que objetiva descrever as orações complexas do kaingang; dentre elas estão as orações relativas, que serão abordadas neste artigo. Os dados analisados foram coletados com informantes bilíngues da Terra Indígena Apucaraninha, localizada no município de Tamarana-PR. Além de contribuir com os estudos no nível morfossintático da língua, esperamos que nossa pesquisa possa colaborar com os estudos comparativos da família linguística Jê e sirva como auxílio na elaboração de material de fácil acesso a professores bilíngues das escolas indígenas do Norte do Paraná. Também almejamos contribuir com o projeto desenvolvido pelo professor Ludoviko dos Santos (UEL) que consiste na elaboração de uma gramática pedagógica da língua kaingang. 
A fundamentação teórica adotada para a análise das orações relativas segue os pressupostos da Linguística Descritiva e Funcional. Para isso, o trabalho apoia-se em Givón (1979), Keenan (1985), Keenan e Comrie (1997), Payne (1997) e Andrews (2007).

\section{Informações Gramaticais Gerais da Língua Kaingang}

Para auxiliar na compreensão da descrição e análise das orações relativas da língua kaingang (seção 2), apresentaremos, de forma sucinta, algumas informações gramaticais da língua, tais como: ordem oracional, tempo, aspecto, modo e marcação de caso.

\subsection{Ordem oracional}

A ordem oracional canônica da língua kaingang é SOV. Essa ordem ocorre, preferencialmente, quando o sujeito é nominal. Nessa estrutura, geralmente o sujeito é marcado morfologicamente, como demonstra o seguinte exemplo:

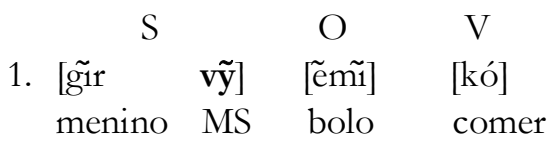

"O menino comeu bolo."

O kaingang constitui-se como uma língua posposicional, portanto, o marcador de sujeito segue o núcleo do sintagma nominal. No exemplo acima, ocorre o marcador $v \tilde{y}$ que, segundo Wiesemann (2002), indica sujeito tópico.

O objeto direto sempre antecede o verbo e não é seguido por posposição, sendo, portanto, uma posição fixa na língua. O objeto indireto, quando ocorre, é seguido pela posposição mỹ (para), como mostra o exemplo 2.

$\begin{array}{llll}\mathrm{S} & \mathrm{OI} & \mathrm{OD} & \mathrm{V}\end{array}$

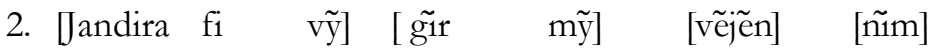
Jandira FEM MS menino POSP comida dar "Jandira deu comida para o menino." 
É possível constatar a presença da partícula fi. Essa partícula funciona como pronome pessoal de terceira pessoa - ela -, como pronome possessivo de terceira pessoa no singular - dela - e também é usada como marcador de feminino ${ }^{1}$, como no exemplo 2.

$\mathrm{Na}$ oração intransitiva, a ordem básica é SV, como mostra o exemplo 3.
$\mathrm{S} \quad \mathrm{V}$

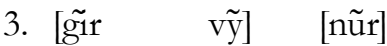
menino MS dormir
"O menino dormiu."

De acordo com Abreu (2009), quando o sujeito é pronominal, a ordem básica é OVS. Quando ocorre nessa ordem, o sujeito não recebe marca morfológica como acontece com o sujeito nominal.
$\mathrm{O} \quad \mathrm{V} \quad \mathrm{S}$
4. [gãr] [tu] [ti]
milho carregar P3P
"Ele carregou milho." (ABREU, 2009, p. 39)

Ainda com relação ao sujeito pronominal, de acordo com Abreu (2009), quando a oração apresenta objeto indireto, a ordem básica passa a ser OI S OD V.
OI
S
OD
$\mathrm{V}$
5. [inh mỹ] [ti] [manỹnỹ] [vã]
P1P POSP P3P banana carregar
"Ele carregou banana para mim." (ABREU, 2009, p. 36)

${ }^{1}$ Para maiores informações sobre essa marcação, sugerimos a leitura de "Gênero em Kaingang?”, de Wilmar da Rocha D'Angelis (2002), disponível em $<$ www.portalkaingang.org>. 


\subsection{Considerações sobre tempo, aspecto e modo}

Conforme apontam os trabalhos de Wiesemann (2002), Gonçalves (2007, 2011) e Almeida (2008), a língua kaingang marca tanto gramatical como lexicalmente as categorias de tempo, aspecto e modo (TAM), de forma que o verbo pode ou não sofrer flexão e ser acompanhado de partículas que indicam aspecto e modo.

Almeida (2008) explica que, do ponto de vista morfológico/ gramatical, o kaingang apresenta apenas dois tempos: (i) futuro - tempo marcado, e (ii) não futuro - tempo não marcado. A autora postula que essa distinção demonstra um contraste mais modal do que temporal, de forma que o tempo futuro expressa o modo irrealis (algo que ainda não aconteceu) e o não futuro o modo realis (algo que aconteceu, acontece normalmente ou está acontecendo). No modo realis, que distingue entre perfectivo e imperfectivo, a autora constatou que o verbo pode ser flexionado em -g e ser acompanhado dos marcadores de aspecto que indicam imperfectivo $(m \tilde{u}, \tilde{t}, \tilde{m} \tilde{\imath})$ ou não ser flexionado em construções perfectivas, as quais não apresentam marcador. Já no modo irrealis, o verbo, normalmente,

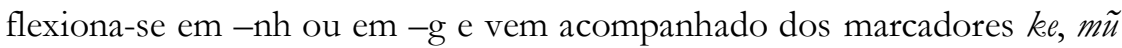
e $t \tilde{u} \tilde{n}$. O quadro 1 apresenta a regra geral de flexão verbal e os marcadores usados nos modos realis e irrealis, conforme a análise de Almeida (2008).

Quadro 1 - Regra geral de flexão verbal e marcadores nos modos realis e irrealis

\begin{tabular}{|c|c|c|}
\hline Modo & Flexão verbal & Marcadores \\
\hline Realis & $-\mathrm{g}$ ou $\varnothing$ & $m \tilde{u}, t \tilde{\imath}, n \tilde{\imath}, \varnothing$ \\
\hline Irrealis & $-\mathrm{nh} \mathrm{ou}-\mathrm{g} /-\mathrm{j}$ & $k e, m \tilde{u}, t \tilde{u} n \tilde{\imath}$ \\
\hline
\end{tabular}

Fonte: Almeida (2008, p. 91)

Gonçalves (2011), diferente de Almeida (2008), reconhece que os verbos podem apresentar marca morfológica para expressar referência temporal passada. A autora apresenta as seguintes constatações a respeito da expressão de tempo na língua kaingang: 
a) expressão temporal (lexical) a partir da utilização de adjuntos temporais apontando anterioridade, posterioridade ou simultaneidade ao $\mathrm{MF}^{[2]}$;

b) verbos que possuem uma forma própria para expressar Tempo Passado;

c) referência temporal passada expressa morfologicamente por $\{-\boldsymbol{g}\}$ acrescido a alguns verbos e a alguns aspectuais;

d) referência temporal passada com a utilização de ja junto a Verbos e Nomes;

e) referência temporal futura expressa morfologicamente por $\{-\boldsymbol{j}\}$ acrescido a verbos terminados em vogais; ou a marcadores aspectuais, ou ainda acrescido a alguns nomes;

f) referência temporal futura e a utilização de Perfectivos;

g) outras formas verbais que assinalam ações ocorridas ou 'por acontecer'. (GONÇALVES, 2011, p. 27, grifos da autora)

Os quadros 2 e 3 sistematizam as categorias de TAM, conforme a análise de Almeida (2008) e Gonçalves (2011), respectivamente.

Quadro 2 - Sistematização de modo e aspecto do kaingang

\begin{tabular}{|c|c|c|c|c|c|c|c|}
\hline \multirow[t]{2}{*}{ MODO } & \multicolumn{4}{|c|}{ Realis } & \multirow[t]{2}{*}{ Irrealis } & \multicolumn{2}{|c|}{ Imperativo } \\
\hline & & & & & & pedido & ordem \\
\hline \multirow{2}{*}{ ASPECTO } & \multirow[b]{2}{*}{ Perfectivo } & \multicolumn{3}{|c|}{ Imperfectivo } & & & \\
\hline & & $\begin{array}{c}\text { continuativo/ } \\
\text { incoativo }\end{array}$ & habitual & estativo & & & \\
\hline MARCADORES & $\varnothing$ & mũ & tĩ & nĩ & $\begin{array}{c}\operatorname{ke}(m \tilde{u}) \\
\text { nĩ } \\
(\text { tũ nĩ) }\end{array}$ & $\varnothing$ & $\mathrm{ra}, \mathrm{rỹ}$ \\
\hline
\end{tabular}

Fonte: Almeida (2008, p. 112)

${ }^{2}$ A abreviatura MF corresponde a Momento da Fala. 
Quadro 3 - Categorias TAM na língua kaingang

\begin{tabular}{|c|c|c|c|c|c|}
\hline & $\begin{array}{c}\text { Fonte lexical } \\
\text { (para as } \\
\text { gramaticalizações) }\end{array}$ & Tempo & Aspecto & Modo & Modalidade \\
\hline$j a$ & ?? & $\begin{array}{l}\text { Passado } \\
\text { (Verbos e } \\
\text { Nomes) }\end{array}$ & $\begin{array}{c}\text { Perfectivo/ } \\
\text { Perfeito }\end{array}$ & & $\begin{array}{l}\text { Possibilidade de } \\
\text { expressar } \\
\text { modalidade em } \\
\text { contextos futuros }\end{array}$ \\
\hline$\{-j\}$ & --- & $\begin{array}{l}\text { Futuro } \\
\text { (Verbos, } \\
\text { Nomes e } \\
\text { Aspectos) }\end{array}$ & & & \\
\hline$\{-g\}$ & --- & $\begin{array}{l}\text { Passado } \\
\text { (Verbos, } \\
\text { Nomes e } \\
\text { Aspectos }\end{array}$ & & & \\
\hline$m \tilde{u}$ & verbo 'ir.PL' & & Perfectivo & & $\begin{array}{c}\text { Possibilidade de } \\
\text { expressar } \\
\text { modalidade em } \\
\text { contextos futuros }\end{array}$ \\
\hline$t \tilde{\imath}$ & verbo 'ir. SG' & & $\begin{array}{c}\text { Imperfectivo } \\
\text { Habitual }\end{array}$ & & \\
\hline $\mathrm{ra}$ & CONJ: se & & & COND & \\
\hline $\mathrm{ra}$ & & & & Imperativo & \\
\hline$v \tilde{e}$ & $?$ & & & & $\begin{array}{l}\text { Modalidade } \\
\text { epistêmica: } \\
\text { - Assertivo; } \\
\text { - Contrafactual }\end{array}$ \\
\hline
\end{tabular}

Fonte: Gonçalves (2011, p. 274)

É possível perceber que as autoras divergem quanto ao emprego do

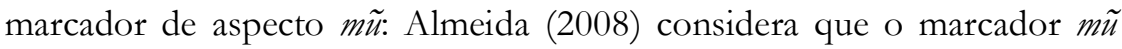
indica imperfectividade, marcando uma das fases do evento (começo, meio o fim); para Gonçalves (2007), esse mesmo marcador indica perfectividade, assinalando a completude do evento, o fim da ação, também podendo ocorrer em contextos futuros marcando a completude do evento num momento posterior. Nos dados analisados neste artigo, consideramos que este marcador assinala a completude do evento.

\subsection{Marcação de Caso}

A principal característica que compreende os sistemas de marcação de caso nas línguas é a maneira como elas distinguem as seguintes funções 
sintático-semânticas: A - sujeito de verbo transitivo; S - sujeito de verbo intransitivo (único argumento de verbo intransitivo); e $\mathrm{O}$ - objeto de verbo transitivo (semanticamente paciente de verbo transitivo).

Com base nessa diferenciação, há dois principais sistemas constatados nas línguas: nominativo-acusativo e ergativo-absolutivo. De acordo com Dixon (1994), as línguas que tratam S e A da mesma forma, diferenciando o argumento $\mathrm{O}$, exibem o sistema nominativo-acusativo $(\mathrm{S}=\mathrm{A} \neq \mathrm{O})$; enquanto as línguas que tratam $\mathrm{S}$ e $\mathrm{O}$ da mesma forma, diferenciando o argumento A, exibem o sistema ergativo-absolutivo $(S=O \neq A)$. A marcação de caso pode se manifestar de três formas: (i) no SN por meio da presença ou da ausência de uma marca morfológica; (ii) na concordância verbal; (iii) na ordem de constituintes.

Em muitas línguas, os dois sistemas existem lado a lado, resultando num sistema misto. A língua kaingang, por exemplo, exibe o sistema nominativo nas orações simples e, nas orações complexas que apresentam orações subordinadas, exibe um sistema de marcação de caso na oração principal e outro na oração subordinada.

Nas orações simples, a língua trata A e S da mesma forma, diferenciando-os de $\mathrm{O}$, ou seja, nessas orações, a marcação nominal exibe o sistema nominativo-acusativo.
6. $\tilde{\text { gir }}$
vy
prẽr
menino MS-NOM gritar
"O menino gritou."

7. mig vy $\tilde{y}$ gir- $\varnothing \quad$ prã $^{-}$

onça MS-NOM menino-AC morder

"A onça mordeu o menino."

Como se pode observar nestes exemplos, tanto S (ex.: 6), quanto A (ex.: 7) exibem o mesmo marcador $-v \tilde{y}$. O objeto direto no exemplo 7 exibe marcação zero, pois este argumento não é marcado na língua. As duas orações simples (6 e 7) atribuem, portanto, marcação de caso aos argumentos $\mathrm{S}, \mathrm{A}$ e $\mathrm{O}$ de acordo com o sistema nominativo-acusativo. Assim S e A exibem o marcador nominativo ṽy, enquanto $\mathrm{O}$ apresenta marcação zero.

Seguem alguns exemplos de orações complexas que demonstram um sistema misto de marcação nominal de caso. 


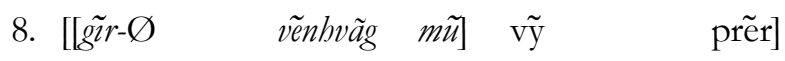
menino-ABS correr ASP MS-NOM gritar "O menino que correu gritou."

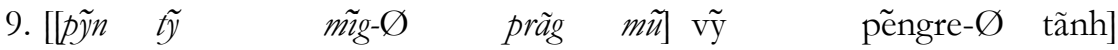
cobra MS-ERG onça-ABS morder ASP MS-NOM galinha-AC matar "A cobra que mordeu a onça matou a galinha."

Nos exemplos acima, as orações principais e as subordinadas estão separadas por colchetes, sendo que as orações relativas (orações subordinadas) estão destacadas em itálico para melhor identificação. Nesses exemplos, é a oração relativa que ocupa a posição de sujeito da oração principal ${ }^{3}$, funcionando, portanto, como S, em 8, e A, em 9. Em ambos os exemplos, o sujeito da oração principal, seja $\mathrm{S}$ ou $\mathrm{A}$, exibe a marca de nominativo $v \tilde{y}$, enquanto o objeto direto da oração principal, em 9 - pẽngre -, não é marcado. Observa-se, portanto, que a marcação dos argumentos da oração principal, nesses exemplos, exibe o sistema nominativo-acusativo tratando $\mathrm{S}=\mathrm{A} \neq \mathrm{O}$. Nesses mesmos exemplos, a marcação dos argumentos da oração subordinada (relativa) exibe o sistema ergativo-absolutivo: em 9, o argumento A recebe a marca de sujeito ergativo - ty - enquanto o argumento $S$ de 8 não recebe marcação, sendo tratado da mesma forma que o argumento $\mathrm{O}$, ou seja, ambos exibem o caso absolutivo. Assim, é possível observar que a oração subordinada desses exemplos exibe um sistema diferente da oração principal, pois trata $S=O \neq A$. Segundo Givón (2001), a marcação ergativa ocorre somente no sujeito na oração transitiva, enquanto o objeto da oração transitiva e o sujeito da intransitiva recebem a marcação absolutiva que, geralmente, é zero. Nos exemplos do kaingang, a marcação de caso absolutivo sempre será zero.

Enfim, os exemplos 8 e 9 mostram que a língua kaingang exibe dois sistemas de marcação de caso quando o período apresenta uma oração subordinada. De acordo com Dixon (1994), o emprego de mais de um sistema pode ser condicionado por quatro características: (i) natureza semântica do verbo principal; (ii) natureza semântica do núcleo do $\mathrm{SN}$; (iii) tempo, aspecto ou modo da oração e; (iv) status gramatical da oração (se é

${ }^{3}$ Explicaremos isso detalhadamente na seção 2. 
principal ou subordinada). É possível perceber que, na língua kaingang, o sistema misto é condicionado pelo status gramatical da oração, de forma que a oração principal exibe um sistema e a subordinada outro.

Dixon (1994) afirma que as orações principais, sejam acusativas ou ergativas, exibem uma marcação oposta àquela da oração subordinada quando a língua emprega um sistema cindido. Uma das línguas citadas como exemplo pelo autor é o xokleng ${ }^{4}$ : segundo Dixon (1994), as orações principais podem ser ergativas ou absolutivas - cisão condicionada pelo aspecto -, no entanto, as orações subordinadas são sempre ergativas.

\section{Descrição e Análise das Orações Relativas da Língua Kaingang}

As orações relativas têm a função de modificar o núcleo de um sintagma nominal presente na oração principal. Dessa forma, conforme aponta Payne (1997), um período composto que apresenta uma oração relativa constitui-se por: (i) o núcleo do SN que é modificado pela oração relativa; (ii) a oração relativa (doravante OR) que restringe esse núcleo e; (iii) um SN relativo que é correferente com o núcleo do $\mathrm{SN}$ da oração principal.

Autores que abordam as orações relativas sob a perspectiva funcional, tais como Givón (1979), Keenan (1985), Keenan e Comrie (1997), Payne (1997) e Andrews (2007), postulam que as línguas podem empregar estratégias diferentes na formação de orações relativas. Assim, há quatro parâmetros que permitem distinguir as orações relativas nas línguas: (i) a posição da oração relativa em relação ao núcleo nominal a ser relativizado; (ii) quais posições sintáticas podem ser relativizadas; (iii) o tipo de marcador relativo; (iv) o modo de expressão do SN relativizado - estratégias de recuperação de caso. É com base nesses parâmetros que organizamos a descrição e análise das orações relativas da língua kaingang.

\subsection{Posição da oração relativa em relação ao núcleo nominal a ser relativizado}

Conforme a posição que a oração relativa ocupa em relação ao núcleo nominal relativizado, Keenan (1985) distingue dois tipos de orações relativas:

${ }^{4}$ Língua da família Jê semelhante ao kaingang. 
(i) externas - cujo núcleo nominal ocorre fora da oração relativa e; (ii) internas - nas quais o núcleo nominal ocorre dentro da oração relativa. Além dessas, Payne (1997) e Andrews (2007) também tratam das orações relativas sem núcleo. As orações relativas externas são divididas em dois tipos: (i) pré-nominais - ocorrem antes do núcleo nominal; e (ii) pós-nominais ocorrem após o núcleo nominal.

$\mathrm{Na}$ língua kaingang, constatamos a ocorrência de orações relativas internas, como se pode observar nos seguintes exemplos ${ }^{5}$ :

10. $\left[\begin{array}{lllll}g \tilde{\text { ir }} & f \tilde{y} & \text { mũ } & \tilde{\mathrm{y}} & \text { nũr }\end{array}\right]$ menino chorar ASP MS dormir "O menino que chorou dormiu."

11. [lgĩ ty mora nig mũ vỹ pévé] menino MS bola dar pontapé ASP MS escorregar "O menino que chutou a bola caiu."

12. [[gir ty mora nig mĩ vy gol han] menino MS bola dar pontapé ASP MS gol fazer "O menino que chutou a bola fez o gol."

13. [Pedro vỹ $\left[\begin{array}{llllll}\mathbf{m i g} \boldsymbol{g} & \tilde{y} & \tilde{g} \mathrm{r} & \text { prãg } & \text { mĩ }\end{array}\right]$ Pedro MS onça MS menino morder ASP matar "Pedro matou a onça que mordeu o menino."

Nota-se que a oração relativa ocupa a posição que o núcleo nominal relativizado ocuparia na oração principal. Em 10, 11 e 12 ocupa a posição de sujeito e em 13 ocupa a posição de objeto. A oração relativa constitui-se de uma sentença completa e apresenta o marcador de aspecto contínuo mü. No decorrer deste trabalho, repetiremos os exemplos acima juntamente a outros para explicar a marcação de caso, a estratégia de relativização empregada pela língua e a marcação do núcleo nominal na oração principal.

${ }^{5}$ Nos exemplos que compõem esta seção, o núcleo nominal relativizado aparece em negrito e a oração relativa em itálico. A divisão entre a oração principal e a relativa se dá por meio de colchetes. 


\subsection{Posições sintáticas relativizáveis e estratégia de relativização}

O segundo parâmetro que permite distinguir as orações relativas nas línguas diz respeito a quais posições sintáticas podem ser relativizadas. Esse parâmetro tem como base a Hierarquia de Acessibilidade de Kenan e Comrie (1977):

sujeito $>$ objeto direto $>$ objeto indireto $>$ oblíquo $>$ genitivo $>$ comparativo

Keenan e Comrie (1977) destacam que, se uma posição sobre esta hierarquia é relativizável, todas as posições à esquerda também serão, embora a estratégia de relativização possa ser diferente. De acordo com os autores, há línguas que permitem somente a relativização do sujeito e ressaltam que, se uma posição mais à direita da hierarquia for relativizável, todas as posições anteriores a ela também serão.

Conforme Keenan (1985), a posição de sujeito é a mais relativizável nas línguas, no entanto, pode haver diferença na relativização de diferentes tipos de sujeito, de forma que o sujeito de verbos intransitivos são mais relativizáveis que os de verbos intransitivos.

Juntamente com as posições relativizáveis, trataremos do comportamento da língua com relação ao terceiro e quarto parâmetros.

O terceiro parâmetro diz respeito à natureza do marcador de relativas. Andrews (2007) diz ser comum o emprego de um marcador exclusivo de orações relativas ou o emprego de um marcador que também possa ocorrer em outras orações subordinadas. Payne (1997) denomina esse marcador como relativizador, podendo também ter a forma de um complementizador, como o that (que) do inglês. No português, temos o marcador que, considerado um relativizador na oração relativa e um completizador nas orações subordinadas completivas. Como se verá nos dados, o kaingang não emprega um marcador específico de oração relativa.

O último parâmetro diz respeito ao modo de expressão do $\mathrm{SN}$ relativizado, ou seja, qual é a maneira empregada por determinada língua para lexicalizar a função do núcleo nominal relativizado na oração relativa. As diferentes maneiras de expressar o núcleo na OR são referidas como estratégias de relativização. Keenan (1985) aponta quatro estratégias distintas: (i) retenção pronominal: envolve o emprego de um pronome pessoal na 
OR que é correferente com o núcleo nominal da oração principal; (ii) lacuna: o núcleo nominal não é expresso na OR; (iii) pronome relativo: envolve o emprego de elementos pronominais que ocorrem nas orações relativas e que se diferem dos pronomes pessoais usados em orações simples e; (iv) não redução: diz respeito à expressão completa do núcleo nominal dentro da OR, sendo restrita às orações de núcleo interno. Andrews (2007), além destas, apresenta mais duas estratégias: nominalização e redução. $\mathrm{Na}$ nominalização, a estrutura da oração passa por uma conversão do tipo nominal. As orações reduzidas: (i) apresentam restrição na marcação de tempo, modo e aspecto; (ii) têm formas verbais com características de adjetivos ou morfologia nominal; (iii) carecem de certos componentes sintáticos como marcadores de tempo e constituintes auxiliares encontrados em orações não reduzidas; (iv) ocorrem na posição de adjetivos; (v) apresentam restrições quanto à posição que pode ser relativizada (geralmente permitem apenas as funções de sujeito e de objeto); (vi) são comuns na posição pré-nominal. Givón (1979), assim como Andrews (2007), também considera a nominalização como uma estratégia. Na língua kaingang, pudemos constatar que a estratégia empregada é a de não redução, como poderá ser constatado na análise dos dados.

Para coletar os dados, primeiramente procuramos contemplar as posições da Hierarquia de Acessibilidade (H.A.) de Keenan e Comrie (1977). Assim, com base nas posições relativizáveis, buscamos verificar como a língua se comporta em relação aos demais parâmetros.

Como mencionamos na seção 2.1, constatamos a ocorrência de orações relativas internas, ou seja, com a expressão completa do núcleo nominal dentro da oração relativa. Assim, a estratégia de relativização da língua kaingang é a de não redução, já que o núcleo nominal ocorre completamente expresso na oração relativa. Givón (1979) esclarece que, nesse tipo de estratégia, o núcleo nominal correferente na oração principal é eliminado ou pronominalizado. Desse modo, já que o núcleo nominal é eliminado da oração principal, a lacuna deixada por ele nesta oração é preenchida pela oração relativa. Como poderá ser observado nos dados, a língua kaingang não apresenta uma relativização formal, ou seja, com o emprego de algum relativizador. Baseando-nos em Oliveira (2011) ${ }^{6}$,

${ }^{6}$ A autora trata da relativização de 30 línguas brasileiras, com base em descrições feitas previamente como gramáticas, teses e outros tipos de manuais descritivos. 
percebemos que a maioria das línguas indígenas brasileiras emprega a estratégia da nominalização e apenas três empregam a estratégia de pronome relativo, considerada a estratégia mais formal. É possível constatar que, no kaingang, a subordinação da oração relativa à oração principal se dá em termos semânticos. Embora não ocorram marcas gramaticais no sintagma nominal relativizado, a oração relativa cumpre seu papel de modificadora, atendendo aos propósitos comunicativos.

Quando se trata de posições relativizáveis, é preciso ter em mente que a função do núcleo nominal nem sempre é a mesma na oração principal e na oração relativa. Apresentaremos as posições relativizáveis do kaingang com base na função que o SN relativizado tem na oração principal, já que a relativa é uma oração subordinada que preenche a lacuna deixada por esse sintagma na oração principal.

Com relação à relativização do sujeito, organizamos os dados de forma a contemplar a função sintático-semântica desse argumento: (i) S sujeito de verbo intransitivo e (ii) A - sujeito de verbo transitivo, pois, como já mencionamos na seção 1.3, a língua kaingang diferencia a marcação de caso atribuída a esses argumentos na oração principal e na subordinada.

\subsubsection{Posições relativizáveis quando o SNé S da oração principal}

Quando a lacuna deixada pelo SN na oração principal ocorre na posição de $\mathrm{S}$, é possível relativizar as seguintes posições referentes à H.A.: sujeito, objeto direto, objeto indireto, constituinte oblíquo e genitivo. A oração relativa preenche a lacuna deixada pelo sujeito na oração principal.

\subsubsection{SN é S na relativa}

14. $\left[\begin{array}{lllll}\text { gĩr } & f y & \text { mũ }\end{array} \quad\right.$ vỹ nũr $]$ menino chorar ASP MS dormir "O menino que chorou dormiu."

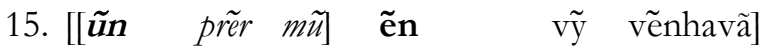
alguém gritar ASP PR.DEM MS correr "Aquele que gritou correu." 
Estes dados mostram que o $\mathrm{SN}$ relativizado tem a função de $\mathrm{S}$ tanto na oração principal quanto na relativa, de forma que a oração relativa ocupa a posição de sujeito. A estratégia de relativização é a de não redução, de maneira que o SN ocorre totalmente expresso na oração relativa e, na oração principal, é eliminado (ex.: 14) ou retomado por meio do pronome demonstrativo én (aquele) (ex.: 15). Este pronome ora ocorre, ora não, portanto, não parece se tratar de algo obrigatório. Acreditamos que a motivação de sua ocorrência seja apenas uma questão de ênfase.

Quanto à marcação de caso atribuída ao sujeito, é possível constatar que: (i) na oração principal, o sujeito, que corresponde à oração relativa, recebe o marcador de nominativo ṽy; (ii) na oração relativa, o sujeito, cuja função sintático-semântica é $\mathrm{S}$, não é marcado, por exibir a marcação de caso absolutivo, que é zero. Como mencionamos na seção 1.3, a língua kaingang exibe o sistema nominativo-acusativo nas orações principais e o sistema ergativo-absolutivo nas orações subordinadas. Com base em Dixon (1994), é possível constatar que o emprego de dois sistemas é condicionado pelo status gramatical da oração, de maneira que a oração principal exibe um sistema e a subordinada outro. Assim, o sujeito da oração principal, independente de ser $\mathrm{S}$ ou $\mathrm{A}$, exibe a marca de nominativo $v \tilde{y}$, enquanto na subordinada exibe o marcador ergativo $t \tilde{y}$, quando é um argumento A, e marcação zero, quando é um argumento $\mathrm{S}$.

\subsubsection{SN é A na relativa}

16. [[ũun gré tỹ kãkénh kajãm mũ vỹ jun] homem MS barco comprar ASP MS chegar "O homem que comprou o barco chegou."

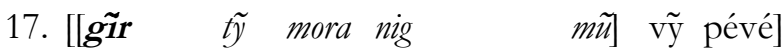
menino MS bola dar pontapé ASP MS escorregar "O menino que chutou a bola caiu."

18. [ [ [ming onça MS menino morder ASP MS morrer "A onça que mordeu o menino morreu." 


\section{9. [[gir ty pó fón mĩ ẽn vy pév $]$ menino MS pedra jogar ASP PR.DEM MS escorregar "O menino que jogou a pedra caiu" \\ (lit.: "Aquele menino que jogou a pedra caiu.")}

Assim como nos exemplos apresentados em 2.2.1.1, a oração relativa ocupa a lacuna deixada pelo argumento $S$ da oração principal. A estratégia de relativização também é a de não redução, pois o sintagma relativizado ocorre totalmente expresso na oração relativa e é eliminado (ex. 16, 17 e 18) ou retomado por meio do pronome ẽn (ex.: 19) na oração principal. O termo relativizado tem função de $\mathrm{S}$ na oração principal e de A na relativa, ocupando, portanto, a posição de sujeito nesta oração.

$O$ fato de a oração relativa nos exemplos acima apresentar dois argumentos - A e $\mathrm{O}$ - e de não apresentar nenhum relativizador acompanhando o SN relativizado, pode levar a certa dificuldade em saber qual dos dois argumentos é o relativizado. Assim, quem não é falante da língua, ao se deparar com os exemplos acima, poderia ficar em dúvida se quem morreu no exemplo 18 foi a onça ou o menino. Perguntamos ao informante como ficaria a frase se fosse o menino que tivesse morrido e ela ficaria exatamente da mesma forma (cf. exemplo 20, a seguir). Perguntamos, então, como ele e os demais falantes sabem sobre quem se trata a afirmação e ele disse que há uma diferença na maneira de "falar". Assim, solicitamos que ele lesse a frase, mostrando quando é o menino que morre e quando é a onça. Ao ler as frases, percebemos uma entonação mais acentuada no SN relativizado.

Em virtude disso, fomos buscar na pragmática um apoio teórico para lidar com esse fato, já que constatamos que o $\mathrm{SN}$ relativizado não recebe marca gramatical, sendo a entonação uma característica importante para marcá-lo. Segundo Levinson (1983 apud PAYNE, 1997, p 261), “a pragmática é a prática de interpretação do enunciado", de maneira que todo enunciado ocorre num determinado contexto e sua interpretação é afetada por ele. Embora os exemplos do kaingang sejam apresentados neste artigo de forma isolada, é claro que houve um contexto para sua elaboração. Durante a coleta, ao interagirmos com o informante, sempre procurávamos

${ }^{7}$ No original: "Pragmatic is the practice of utterance interpretation." 
criar uma situação discursiva contextualizada para, então, chegarmos à frase com a oração relativa.

Givón (2001) aponta três maneiras que podem enfatizar um determinado sintagma numa oração: entonação, ordem de palavras e morfologia. Das três, o autor afirma que a entonação é, perceptivelmente, a mais destacável e está sempre presente independentemente do emprego simultâneo das outras duas. Com base em Bolinger (1985), Givón (2001, p. 249-250, grifos do autor) salienta que:

... a entonação é, provavelmente, o mais consistente e transparente dispositivo icônico de codificação da linguagem, um dispositivo cujas raízes remontam ao sistema gestual. Seu poder icônico reside na dimensão cognitiva da atenção e memória:

\section{Quantidade de código, atenção e memória:}

- A codificação mais distinta e mais proeminente atrai mais atenção.

- A informação que atrai mais atenção é memorizada, armazenada e recuperada de forma eficiente. ${ }^{8}$

É possível concluir que, como os constituintes na oração relativa se mantêm na ordem canônica da língua (SOV) e como não há relativizador, são o contexto e a entonação que permitem distinguir o $\mathrm{SN}$ relativizado, de maneira que a modificação exercida pela oração relativa é bem sucedida nos seus propósitos comunicativos, mesmo sem uma marca morfológica específica.

Com relação à marcação de caso, o sujeito da oração principal, que corresponde à oração relativa, recebe a marca de nominativo ỹy e o sujeito da relativa recebe o marcador de sujeito ergativo tỹy, já que é tratado diferentemente de S.

${ }^{8}$ No original: "intonation is probably the most consistently and transparently iconic coding device in language, a device whose roots reach back to the gestural system. Its iconic power resides in the cognitive dimension of attention and memory:

Code-quantity, attention and memory

- More prominent and more distinct coding attracts more attention.

- Information that attracts more attention is memorized, stored and retrieved more efficiently." 


\subsubsection{SN é OD na relativa}

Quando o SN relativizado é S na oração principal e OD na relativa, a oração relativa ocupa a posição de sujeito da oração principal, preenchendo a lacuna deixada por esse argumento, assim como nos exemplos apresentados em 2.2.1.1 e 2.2.1.3.

20. [[ming onça MS menino morder ASP MS morrer "O menino que a onça mordeu morreu."

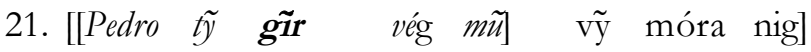
Pedro MS menino ver ASP MS bola dar pontapé "O menino que Pedro viu chutou a bola."

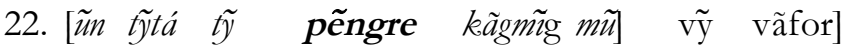
mulher MS galinha pegar ASP MS perdido, "A galinha que a mulher pegou fugiu."

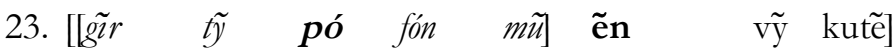
menino MS pedra jogar ASP PR.DEM MS cair "A pedra que o menino jogou caiu."

(lit.: "Aquela pedra que o menino jogou caiu.")

A estratégia de relativização é a de não redução, pois o SN relativizado ocorre totalmente expresso na oração relativa, sendo eliminado na oração principal (exemplos 20, 21 e 22) ou retomado pelo pronome demonstrativo en . Como não há relativizador acompanhando o SN relativizado, a mesma dificuldade apontada em 2.2.1.2 ocorre aqui. Comparando a oração relativa de 18 com a de 20, é possível perceber que elas são idênticas, da mesma forma que a de 19 e a de 23. Mais uma vez são a entonação e o contexto que permitem distinguir qual é o SN relativizado, tornando a modificação exercida pela oração relativa bem sucedida nos seus propósitos comunicativos.

Da mesma forma que nos exemplos apresentados em (b), o sujeito da oração principal, que é ocupado pela oração relativa, exibe a marca de nominativo $\tilde{y}$ e o sujeito da relativa exibe o marcador de ergativo $\tilde{y}$. 


\subsubsection{SN é OI na relativa}

A oração relativa, assim como nos exemplos apresentados em 2.2.1.1, 2.2.1.2 e 2.2.1.3, ocupa a lacuna deixada pelo argumento $S$ da oração principal. Dentro da oração relativa, o SN relativizado tem função de objeto indireto e ocorre na sua posição canônica.

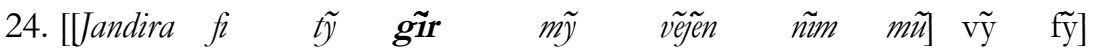
Jandira FEM MS menino POSP comida dar ASP MS chorar "O menino para quem Jandira deu comida chorou."

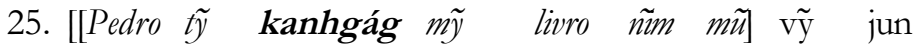
Pedro MS índio POSP livro dar ASP MS chegar "O índio para quem Pedro deu o livro chegou."

Os exemplos acima mostram que a oração relativa ocupa a posição deixada pelo argumento $S$ na oração principal. A estratégia de relativização é a de não redução e o núcleo nominal relativizado é eliminado da oração principal. $\mathrm{Na}$ oração relativa, o $\mathrm{SN}$ relativizado ocorre na sua posição canônica. Como não há um marcador formal para indicar a relativização, novamente o contexto de enunciação aliado à entonação serve para distinguir que o SN relativizado é o objeto indireto.

Com relação à marcação de caso atribuída ao sujeito, o sujeito da oração principal, que corresponde à oração relativa, recebe a marca de nominativo $v \tilde{y}$ e o sujeito da oração relativa recebe o marcador de ergativo $t \tilde{y}$.

\subsubsection{SN é oblíquo na relativa}

Da mesma maneira que nos exemplos anteriores, a oração relativa preenche a lacuna deixada pelo sujeito na oração principal, já que nesta oração o SN relativizado tem função de sujeito. Na oração relativa, o SN relativizado tem função de constituinte oblíquo e ocorre na sua posição canônica, que é a mesma do objeto indireto, ou seja, entre o sujeito e o objeto direto. Assim como o objeto indireto, o constituinte oblíquo é seguido por uma posposição. 


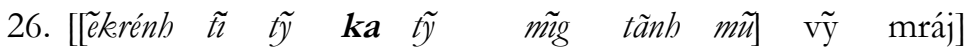
caçador MS pau POSP onça matar ASP MS quebrado "O pau com que o caçador matou a onça quebrou."

A estratégia de relativização é a de não redução, sendo o SN relativizado totalmente expresso na oração relativa e eliminado da oração principal. É possível notar, no exemplo 26, o uso da partícula tỹ como marcador de sujeito e como posposição. Essa partícula, segundo Wiesemann (2002, p. 89) pode funcionar como marcador de sujeito ergativo, como indicador de existência, como indicador de circunstância ("com") e como indicador de tópico. Como posposição, essa partícula corresponde ao que Wiesemann (2002) classifica como indicador de circunstância ("com"). Como discorremos em 2.2.1.2, 2.2.1.3 e 2.2.1.4, pelo fato de a língua não empregar um relativizador e de o SN relativizado ocorrer na sua posição canônica, só é possível distinguir, no exemplo acima, que o $\mathrm{SN}$ relativizado é o constituinte oblíquo por meio do contexto de enunciação e da entonação.

A marcação de caso atribuída ao sujeito também se comporta como nos exemplos anteriores, ou seja, o sujeito da oração principal, que corresponde à oração relativa, exibe a marca de nominativo ṽy, enquanto o sujeito da oração relativa, que é uma oração subordinada, exibe marcador de ergativo $\tilde{y}$, por se tratar de um argumento A.

\subsubsection{SN é genitivo na relativa}

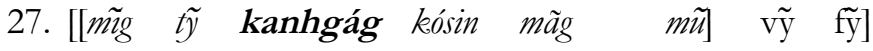
onça MS kaingang filho carregar ASP MS chorar "O índio cujo filho a onça matou chorou."

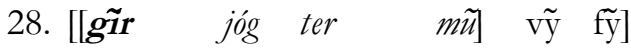
menino pai morrer ASP MS chorar "O menino cujo pai morreu chorou."

Como se pode observar, o caso genitivo, em kaingang, não é expresso por meio de uma marca morfológica. A relação de posse ocorre apenas pela justaposição dos dois nomes: kanhgá kósin (filho do índio), em 27, e gir jóg (pai do menino), em 28. Nos dois exemplos, a oração relativa ocorre na posição de sujeito da oração principal, preenchendo a lacuna deixada por 
esse argumento nessa oração. A estratégia de relativização é a de não redução e, na oração principal, o termo relativizado é eliminado. Na oração relativa do exemplo 27, o SN genitivo ocorre na posição de objeto direto, sendo a entonação e o contexto que permitem saber que o nome relativizado desse sintagma é kanhgág. Na oração relativa do exemplo 28, o SN genitivo ocorre na posição de sujeito e, assim como em 27 , são a entonação e o contexto que permitem distinguir o nome relativizado (gir $)$. Quanto à marcação de caso do sujeito, as orações se comportam como nos exemplos tratados em 2.2.1.1, 2.2.1.2 2.2.1.3, 2.2.1.4 e 2.2.1.5 ou seja, o sujeito da oração principal, que corresponde à oração relativa, recebe a marca de nominativo $y \tilde{y}$. O sujeito da oração relativa recebe marcação conforme o sistema ergativo-absolutivo, ou seja, o argumento A, em 27, recebe o marcador de ergativo - ty - e o argumento $\mathrm{S}$, em 28 , recebe a marcação zero, que corresponde ao caso absolutivo.

\subsubsection{Posições relativizáveis quando o $S N$ é A da oração principal}

Como nos dados apresentados na seção 2.2.1, quando o SN relativizado é o argumento A da oração principal, a oração relativa ocorre na posição de sujeito. $\mathrm{Na}$ oração relativa, o argumento relativizado pode ter função de S ou A.

\subsubsection{SN é $S$ na relativa}

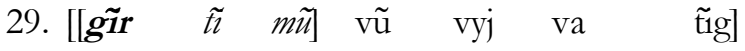
menino ir ASP MS arco carregar andar "O menino que saiu levou o arco."

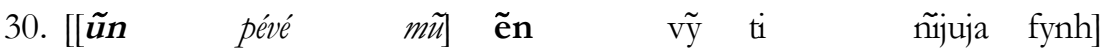
alguém escorregar ASP PR.DEM MS PR.POS dedo cortar "Aquele que caiu cortou o dedo."

(lit.: “Aquele que caiu cortou seu dedo.”)

Como se pode notar, o SN relativizado em 29 e 30 tem a função de $\mathrm{S}$ tanto na oração principal como na relativa, de forma que a oração relativa preenche a lacuna deixada por esse argumento na oração principal. A estratégia de relativização é a de não redução, de maneira que o SN 
relativizado ocorre totalmente expresso na oração relativa e, na oração principal, é eliminado (ex. 29) ou retomado por meio do pronome demonstrativo ẽn (ex. 30).

O sujeito da oração principal, que corresponde à oração relativa, recebe a marca de nominativo $\tilde{y}$, enquanto o da relativa recebe a marcação zero referente ao caso absolutivo, por se tratar de um argumento S.

\subsubsection{SN é A na relativa}

Da mesma maneira que nos exemplos apresentados na seção 2.2.1.2, quando o SN tem função de A na oração principal, ocupa a posição de sujeito desta oração, preenchendo a lacuna deixada por esse argumento. $\mathrm{Na}$ oração relativa, o SN também ocorre na posição de sujeito.

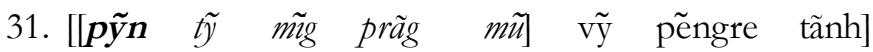
cobra MS onça morder ASP MS galinha matar "A cobra que mordeu a onça matou a galinha."

32. $\left[\begin{array}{lllllll}\boldsymbol{g} \tilde{\mathbf{1}} & t \tilde{y} & \text { mora } & \text { nig } & \text { min } & \text { vy } & \text { gol han }\end{array}\right]$ menino MS bola dar pontapé ASP MS gol fazer "O menino que chutou a bola fez o gol."

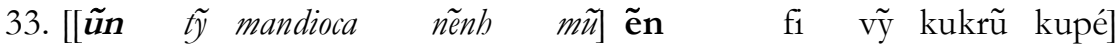
alguém MS mandioca cozinhar ASP PR.DEM FEM MS panela lavar "Aquela que cozinhou a mandioca lavou a panela."

Os exemplos acima se constituem de orações relativas internas, cuja estratégia de relativização empregada é a de não redução, sendo o SN relativizado totalmente expresso na oração relativa e eliminado da oração principal (31 e 32) ou retomado por meio do pronome demonstrativo ẽn (33). O exemplo 31, se considerado isoladamente, pode causar certa dificuldade em identificar se o SN relativizado é o sujeito ou o objeto direto da oração relativa. Como discorremos nas seções 2.2.1.2 e 2.2.1.3, são a entonação e o contexto de enunciação que permitem distinguir que, nessa oração, o SN relativizado é o sujeito.

Com relação à marcação de caso, o sujeito da oração principal, que é preenchido pela oração relativa, recebe a marca de nominativo $v \tilde{y}$ enquanto o sujeito da oração relativa recebe a marca de ergativo fy. 


\subsubsection{Posições relativizáveis quando o $S N$ é $O D$ da oração principal}

Quando o SN relativizado tem função de objeto direto na oração principal, a oração relativa ocupa a lacuna deixada por este argumento, ou seja, a oração relativa ocupa, na oração principal, a posição de objeto direto, independente da função que o núcleo relativizado exerça na relativa. É possível relativizar as seguintes posições referentes à Hierarquia de Acessibilidade: sujeito, objeto direto e objeto indireto.

\subsubsection{SN é S na relativa}

34. [Pedro vỹ [kanhgág ter] vé]

Pedro MS índio morrer ver

"Pedro viu o índio que morreu."

\section{5. [Pedro vỹ [ũn kute mĩ] vé] \\ Pedro MS alguém cair ASP ver \\ "Pedro viu o homem que caiu."}

Nos exemplos acima, o SN relativizado tem função de objeto direto na oração principal e de $\mathrm{S}$ na relativa. A oração relativa ocupa a posição de objeto direto, preenchendo a lacuna deixada por esse argumento na oração principal. Como nos exemplos apresentados nas seções 2.2.1 e 2.2.2, não há emprego de relativizador, ou seja, o $\mathrm{SN}$ relativizado não recebe nenhuma marca gramatical. A estratégia de relativização é a de não redução, pois o SN relativizado aparece completamente expresso na oração relativa, sendo eliminado da oração principal.

Quanto à marcação de caso, o sujeito da oração principal recebe a marca de nominativo ṽy e o sujeito da oração relativa, que corresponde à função S, não é marcado, por corresponder ao caso absolutivo, o qual não recebe marcação.

\subsubsection{SN é A na relativa}

36. José vy $\left[\begin{array}{llllll}\boldsymbol{g i r} & t \tilde{y} & v y j & v a & \tilde{t} g\end{array}\right]$ José MS menino MS arco carregar andar ver "José viu o menino que levou o arco." 


\section{Pedro vỹ $\left[\begin{array}{llllll}\boldsymbol{m i n g} & \text { ty } & \text { gir } & \text { prãg } & \text { mũ } & \text { tãnh}\end{array}\right]$ Pedro MS onça MS menino morder ASP matar "Pedro matou a onça que mordeu o menino."}

Nos exemplos acima, o SN relativizado tem função de objeto direto na oração principal e de A na oração relativa. Como nos exemplos apresentados em 2.2.3.1, a oração relativa ocupa a posição de objeto direto da oração principal, preenchendo a lacuna deixada por esse argumento. A estratégia de relativização também é a de não redução, de forma que o SN relativizado ocorre totalmente expresso na oração relativa e é eliminado da oração principal. Como não há relativizador na oração relativa que identifique o SN relativizado, são o contexto e a entonação que permitem distinguir que o $\mathrm{SN}$ relativizado é o sujeito e não o objeto, de forma que a modificação exercida pela oração relativa atende aos propósitos comunicativos.

$\mathrm{Na}$ oração relativa, o sujeito recebe o marcador de ergativo ty e, na oração principal, recebe o marcador de nominativo $v \tilde{y}$.

\subsubsection{SN é OD na relativa}

38. [Maria fi vỹ [Pedro ty mandioca kufeg mü rynran] Maria FEM MS Pedro MS mandioca descascar ASP ralar "Maria ralou a mandioca que Pedro descascou."

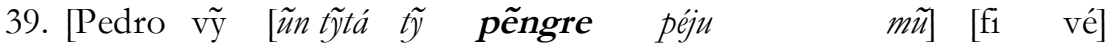
Pedro MS mulher MS galinha roubar/esconder ASP FEM ver "Pedro viu a galinha que a mulher pegou."

Nos exemplos acima, o SN relativizado tem função de objeto direto tanto na oração principal quanto na relativa. A oração relativa ocorre na posição de objeto direto, preenchendo a lacuna deixada por esse argumento na oração principal. Na oração relativa, o SN relativizado ocupa sua posição canônica, ou seja, a de objeto direto. A estratégia de relativização é a de não redução, de maneira que o SN relativizado é completamente expresso na oração relativa e eliminado da oração principal. Da mesma forma que nos exemplos anteriores, não há emprego relativizador para marcar o SN relativizado. 
Como o SN relativizado ocupa sua posição canônica na oração relativa e não é seguido por nenhum relativizador, o exemplo 39, se considerado fora do contexto, poderia causar dúvida em identificar se o $\mathrm{SN}$ relativizado é o sujeito ou o objeto direto. Como já abordamos em exemplos anteriores, o contexto de enunciação do exemplo e a entonação mais acentuada do SN objeto permitem identificá-lo como o SN relativizado.

Quanto à marcação de caso, o sujeito da oração principal recebe a marca de nominativo $v \tilde{y}$, enquanto o sujeito da relativa, que é uma oração subordinada, recebe o marcador de ergativo $\tilde{y}$, tendo em vista que, nos três exemplos, essa posição é ocupada por um argumento A.

\subsubsection{SN é OI na relativa}

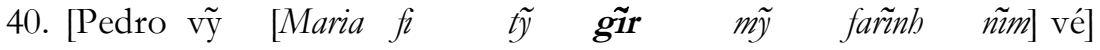
Pedro MS Maria FEM MS menino POSP farinha dar ver "Pedro viu o menino para quem Maria deu farinha."

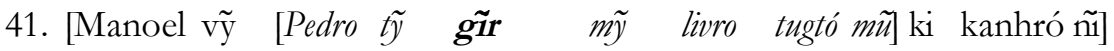
Manoel MS Pedro MS menino POSP livro ler ASP saber ASP "Manoel conhece o menino para quem Pedro leu o livro."

Quando o SN relativizado tem função de objeto direto na principal, a oração relativa ocorre na posição desse argumento. Assim como nos exemplos 24 e 25 , quando o SN tem função de objeto indireto na oração relativa, ele ocorre na sua posição canônica e, já que não há emprego de relativizador para marcá-lo, são o contexto de enunciação e a entonação que possibilitam distingui-lo como SN relativizado.

Da mesma maneira que nos exemplos anteriores, a estratégia de relativização é a de não redução, pois o SN relativizado ocorre totalmente expresso na oração relativa e é eliminado da oração principal. A marcação de caso atribuída ao sujeito também acontece como nos demais exemplos, ou seja, o sujeito da oração principal recebe a marca de nominativo $\tilde{y}$, enquanto o da relativa recebe o marcador de ergativo $t \tilde{y}$.

\subsubsection{Posições relativizáveis quando o SNé OI da oração principal}

Quando o SN relativizado tem função de OI na oração principal, a 
oração relativa preenche a lacuna deixada por esse argumento, ocorrendo, portanto, antes da posposição que o segue. Na oração relativa, o SN relativizado pode ter função de $\mathrm{S}$ e de $\mathrm{A}$.

\subsubsection{SN é S na relativa}

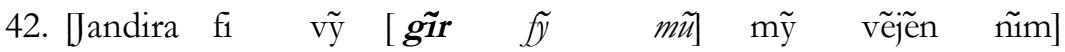
Jandira FEM MS menino chorar ASP POSP comida dar "Jandira deu comida para o menino que chorou."

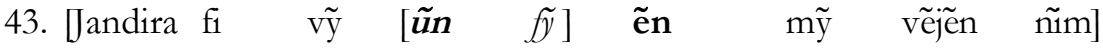 Jandira FEM MS alguém chorar PR.DEM POSP comida dar "Jandira deu comida para aquele chorou.

Nos exemplos acima, o SN relativizado tem função de objeto indireto na oração principal e de $S$ na relativa. A oração relativa ocorre na posição de objeto indireto da oração principal, preenchendo a lacuna deixada por esse argumento nessa oração. $\mathrm{Na}$ oração relativa, o SN relativizado ocorre na posição de sujeito. A estratégia de relativização empregada é a de não redução, sendo que o sintagma nominal relativizado ocorre totalmente expresso na oração relativa e é eliminado no exemplo 42 e retomado por meio do pronome demonstrativo ẽn em 43.

Quanto à marcação de caso, o sujeito da oração principal recebe a marca de nominativo $v \tilde{y}$ e o da relativa, por se tratar de um argumento S, não recebe marcação por exibir o caso absolutivo.

\subsubsection{SN é A na relativa}

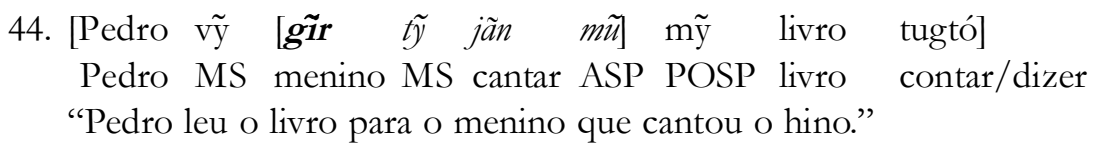

No exemplo acima, o SN relativizado tem função de objeto indireto na oração principal e de A na relativa. A oração relativa preenche a lacuna deixada pelo SN relativizado na oração principal, ocorrendo, portanto, antes da posposição que acompanha esse constituinte. Na oração relativa, o SN relativizado ocorre na posição de sujeito. Como nos demais exemplos 
tratados neste artigo, a estratégia de relativização empregada é a de não redução, que consiste na expressão completa do núcleo nominal na oração relativa e de sua eliminação na oração principal. O sujeito da oração principal recebe o marcador de nominativo $v \tilde{y}$ enquanto o sujeito da relativa recebe o marcador ergativo $t \tilde{y}$.

\section{Considerações Finais}

Com base nos dados apresentados nesse artigo, segue uma síntese de como as orações relativas do kaingang se comportam com relação aos quatro parâmetros que permitem distinguir as orações relativas nas línguas.

Com relação ao primeiro parâmetro, foi possível constatar que a língua kaingang emprega orações relativas internas, já que o núcleo nominal relativizado ocorre dentro dela. No que diz respeito à posição da oração relativa em relação à oração principal, os dados mostram que a oração relativa sempre ocupa a posição correspondente à função que o SN relativizado exerce na principal, independente de sua função na oração relativa. Assim se o $\mathrm{SN}$ relativizado tem na oração principal função de $\mathrm{S}$ ou $\mathrm{A}$, a oração relativa ocupa a posição de sujeito da oração principal; se o SN relativizado tem, na oração principal, a função de objeto direto, a oração relativa preenche essa posição na oração principal; da mesma forma acontece quando o SN relativizado tem função de objeto indireto ou de constituinte oblíquo na oração principal.

Quanto ao segundo parâmetro, organizamos os dados de modo a contemplar quais posições sintáticas podem ser relativizadas partindo da função que o SN exerce na oração principal, já que a relativa é uma oração subordinada que preenche a lacuna deixada por esse sintagma na oração principal. Com relação à relativização do sujeito, consideramos a função sintático-semântica desse argumento: (i) $\mathrm{S}$ - sujeito de verbo intransitivo e (ii) A - sujeito de verbo transitivo, tendo em vista que, nas orações relativas, a língua kaingang exibe o sistema ergativo-absolutivo tratando esses dois argumentos de maneira distinta. Quando o SN relativizado exerce a função de $\mathrm{S}$ na oração principal, é possível relativizar as seguintes posições referentes à Hierarquia de Acessibilidade (H.A.): sujeito (S e A), objeto direto, objeto indireto, constituinte oblíquo e genitivo; quando o $\mathrm{SN}$ relativizado exerce a função de A na oração principal, pode ter na relativa a função de A ou S; quando o SN relativizado tem função de objeto direto na oração principal, 
pode ter, na relativa, função de sujeito ( $\mathrm{S}$ ou $\mathrm{A}$ ), objeto direto e objeto indireto e; quando o $\mathrm{SN}$ relativizado exerce a função de objeto indireto na oração principal, na oração relativa pode exercer a função de sujeito (S ou A). Em todos os exemplos, pode-se observar que, na oração relativa, o SN relativizado ocupa sua posição canônica.

Com relação ao terceiro parâmetro - tipo de marcador relativo - os dados mostram que a língua kaingang não emprega pronome relativo, nem qualquer relativizador que marque o $\mathrm{SN}$ relativizado dentro da oração relativa. Como o SN relativizado ocupa na oração relativa sua posição canônica e como não há emprego de um relativizador, pode haver certa dificuldade (se a frase for considerada fora do contexto) em distinguir o $\mathrm{SN}$ relativizado quando essa oração apresenta dois argumentos, como sujeito e objeto, por exemplo. Assim, é o contexto de enunciação, aliado a uma entonação mais acentuada do $\mathrm{SN}$ relativizado, que permite distinguir qual é o SN relativizado, de maneira que a oração relativa cumpre seu papel de modificadora, atendendo aos propósitos argumentativos.

Quanto ao último parâmetro, que diz respeito ao modo de expressão do SN relativizado, ou seja, às estratégias de recuperação de caso, foi possível constatar que a língua kaingang emprega a estratégia de não redução. Essa estratégia diz respeito à expressão completa do núcleo nominal na oração relativa. Segundo Givón (1979), na oração principal, o núcleo nominal é eliminado ou pronominalizado, de maneira que a oração relativa preenche a lacuna deixada por ele. Os dados coletados mostram que, quando pronominalizado, há o emprego do pronome demonstrativo ẽn (aquele).

Com relação à marcação de caso atribuída ao sujeito, foi possível constatar que a língua emprega o sistema nominativo-acusativo na oração principal. Nesse sistema, os argumentos $\mathrm{S}$ e A recebem o marcador de nominativo $v \tilde{y}$. $\mathrm{Na}$ oração relativa, que é uma oração subordinada, o argumento $\mathrm{S}$ não é marcado por se tratar de caso absolutivo e o argumento A recebe o marcador de ergativo ty.

Enfim, embora não haja uma marca morfológica específica para a oração relativa, é possível constatar que a subordinação dessa oração à oração principal se dá em termos semânticos. Logo, o contexto de enunciação mais a entonação dão conta de atender a função de modificação que a oração relativa exerce, de forma que a estrutura empregada pela língua atende aos propósitos comunicativos. Esperamos que nossa pesquisa possa contribuir 
com o campo da análise e descrição de línguas indígenas que tanto necessita de linguistas voltados a este tipo de pesquisa.

\section{Lista de abreviaturas}

A - sujeito de verbo transitivo

ABS - absolutivo

AC - acusativo

ASP - aspecto

COND - condicional

CONJ - conjunção

ERG - ergativo

H.A. - Hierarquia de Acessibilidade

MS - marcador de sujeito

NOM - nominativo

$\mathrm{O}$ - objeto

OD - objeto direto
OI - objeto indireto

OR - oração relativa

PL - plural

POSP - posposição

PR.DEM - pronome demonstrativo

PR. POS - pronome possessivo

P1P - pronome de primeira pessoa

P3P - pronome de terceira pessoa

$\mathrm{S}$ - sujeito de verbo intransitivo

SG - singular

$\mathrm{SN}$ - sintagma nominal

\section{Referências}

ABREU, E. R. R. Descrição do sistema pronominal na estrutura frasal em kaingang. 2009. Dissertação (Mestrado em Estudos da Linguagem) Universidade Estadual de Londrina, Londrina.

ALMEIDA, L. de. A marcação de (tempo), modo e aspecto na língua kaingang: uma proposta de análise. 2008. Dissertação (Mestrado em Estudos da Linguagem) - Universidade Estadual de Londrina, Londrina.

ANDRADE, T. S. M. de. As orações verbais simples em kaingang: uma proposta de análise. 2012. Dissertação (Mestrado em Estudos da Linguagem) - Universidade Estadual de Londrina, Londrina.

ANDREWS, A. D. Relative clauses. In: SHOPEN, T. (Ed.). Language typology and syntactic description: Volume II - Complex constructions. New York: Cambridge University Press, 2007. p. 206-236. 
BALDUS, H. Vocabulário zoológico kaingáng. Arquivos do Museu Paranaense, Curitiba, v. 6, p. 149-161, 1947.

BOMFOCO, M. A. Ergatividade em kaingáng: um estudo descritivo funcional. 2004. Tese (Doutorado em Linguística) - Pontifícia Universidade Católica do Rio Grande do Sul, Porto Alegre.

CAVALCANTE, M. P. Fonologia e morfologia da lingua kaingáng: o dialeto de São Paulo comparado com o do Paraná. 1987. Tese (Doutorado em Linguística) - Universidade de Campinas, Campinas.

D’ANGELIS, W. da R. Traços de modo e modos de traçar geometrias: línguas Macro-Jê e teoria fonológica. 1998. Tese (Doutorado em Linguística) Universidade de Campinas, Campinas. 2 v.

D’ANGELIS, W. da R. Gênero em kaingang? In: SANTOS, L. C. dos; PONTES, I. (Orgs.). Linguas Jê: estudos vários. Londrina: Eduel, 2002. p. 215-242.

DIXON, R. M. W. Ergativity. Cambridge: Cambridge University Press, 1994.

FLORIANA, Fr. M. B. de V. Ensaio de grammatica kainjang. Revista do Museu Paulista, São Paulo, v. 10, p. 531-563, 1918.

FLORIANA, Fr. M. B. de V. Diccionários Kainjgang - Portuguez e PortuguezKainjgang. Curitiba: Museu Paranaense, 1920.

GIVÓN, T. On understanding grammar. New York: Academic Press, 1979. GIVÓN, T. Syntax: An introduction. v. II. Amsterdam: John Benjamins Publishing Company, 2001.

GONÇALVES, S. A. Aspecto no Kaingáng. 2007. Dissertação (Mestrado em Linguística - Línguas Indígenas) - Universidade Estadual de Campinas, Campinas.

GONÇALVES, S. A. Tempo, aspecto e modo em contextos discursivos no Kaingagn Sul (Jê). 2011. Tese (Doutorado em Linguística) -Universidade Estadual de Campinas, Campinas. 
GUÉRIOS, R. F. M. Estudos sobre a Língua Caingangue. Arquivos do Museu Paranaense, Curitiba, v. 2, p. 97-178, 1942.

GUÉRIOS, R. F. M. O Xokrén é idioma Caingangue. Arquivos do Musen Paranaense, Curitiba, v. 4, p. 321-331, 1945.

KEENAN, E. L. Relative clauses. In: SHOPEN, T. (Ed.). Language typology and syntactic description: Volume II - Complex constructions. Cambridge: Cambridge University Press, 1985. p. 141-170.

KEENAN, E. L.; COMRIE, B. Noun phrase accessibility and universal grammar. Linguistic Inquiry, v. 8, p. 63-100, 1977.

NASCIMENTO, S. H. L. Aspectos morfológicos e sintáticos e marcação de caso da lingua Kaingang. 1995. Dissertação (Mestrado em Linguística) Universidade Federal de Santa Catarina, Florianópolis.

OLIVEIRA, G. M. de. Acessibilidade semântica nas construções relativas em linguas indígenas brasileiras: um estudo tipológico-funcional. 2011.

(Dissertação em Estudos Linguísticos) - Universidade Estadual Paulista Júlio de Mesquita Filho, São José do Rio Preto.

PAYNE, T. E. Describing morphosyntax. Cambridge: Cambridge University Press, 1997.

SEKI, L. Línguas indígenas do Brasil no limiar do século XXI. Revista Impulso, n. 27, p. 233-256, 2000.

SILVA, C. R. História crítica da construção da escrita do Kaingáng. 1996.

Dissertação (Mestrado em Letras) - Universidade Estadual de Londrina, Londrina.

SILVA, Maria S. R. da. A lingua kaingáng da aldeia paulista Icatu: uma descrição funcional. 2011. Tese (Doutorado em Estudos Linguísticos) Universidade Estadual Paulista Júlio de Mesquita Filho, São José do Rio Preto.

SILVA, Moana de L. Análise de bilinguismo na escrita em língua portuguesa de sociedades indígenas Kaingáng. 2011. Dissertação (Mestrado em Linguística Línguas Indígenas) - Universidade Estadual de Campinas, Campinas. 
TABOSA, L. P. Construções causativas da lingua Kaingang. 2006. Dissertação (Mestrado em Estudos da Linguagem) - Universidade Estadual de Londrina, Londrina.

TEIXEIRA, J. B. Contribuição para a fonologia do dialeto Kaingáng de Nonoai (RS). 1988. Dissertação (Mestrado em Linguística - Línguas Indígenas) Universidade Estadual de Campinas, Campinas.

WIESEMANN, U. Die Phonologische und Grammatische struktur der Kaingáng Sprache. Paris: Mounton, 1972.

WIESEMANN, U. Time distinctions in Kaingáng. Zeitschrift für Ethnologie, Braunschweig, v. 99, n. 1-2, p. 120-130, 1974.

WIESEMANN, U. Dicionário Kaingáng-Português, Português-Kaingang. Curitiba: Evangélica Esperança, 2002. 